\title{
Formação em fisioterapia no Brasil: reflexões sobre a expansão do ensino e os modelos de formação
}

\section{Physical therapy education in Brazil: reflections on the expansion of teaching and training models}

\author{
José Patrício Bispo Júnior \\ Professor do Instituto Multidisciplinar em Saúde/ \\ Universidade Federal da Bahia \\ Av. Olívia Flores, 3.000 \\ 45055-090 - Vitória da Conquista - BA - Brasil \\ jpatricio@ufba.br
}

Recebido para publicação em abril de 2008. Aprovado para publicação em abril de 2009.
BISPO JÚNIOR, José Patrício. Formação em fisioterapia no Brasil: reflexões sobre a expansão do ensino e os modelos de formação. História, Ciências, Saúde Manguinhos, Rio de Janeiro, v.16, n.3, jul.-set. 2009, p.655-668.

\section{Resumo}

Discute a formação em fisioterapia no Brasil, problematizando aspectos da expansão do ensino, o campo de atuação e o perfil profissional. A abertura de novos cursos atingiu acelerada expansão a partir de 1997, porém de forma desregulada, com privatização do ensino e concentração geográfica dos cursos. A ampliação do número de cursos e a maior oferta de profissionais não resultaram em maior acesso da população à assistência em fisioterapia. O modelo da formação adotado tem sido o curativoreabilitador privatista, inadequado à nova realidade epidemiológica e ao atual modelo de atenção à saúde. Observam-se, nos últimos anos, o surgimento de iniciativas de mudanças no ensino da fisioterapia e a construção de outro perfil profissional.

Palavras-chave: fisioterapia; educação superior; formação profissional; ensino da saúde; Sistema Único de Saúde.

Abstract

This article on physical therapy education in Brazil focuses on the expansion of teaching, field of activities, and professional profile. The number of PT courses began multiplying rapidly in 1997, but the process lacked regulation and entailed both privatization of education and a geographic concentration of courses. This increase in both courses and trained physical therapists did not redound in greater access to PT services. The privatist curative -rehabilitation model that has been adopted is not appropriate to the new epidemiological reality or to current healthcare standards. Recent years have seen initiatives to bring change to physical therapy education and build a new professional profile.

Keywords: physical therapy; higher education; professional training; health education; Unified Healthcare System. 
A sociedade contemporânea passa por complexas e significativas transformações em face da reestruturação produtiva do capitalismo global. Mudanças na economia e nas relações internacionais, os avanços científicos e tecnológicos e o desenvolvimento de diferentes relações de produção impuseram nova ordem de organização econômica e política, com reflexos em vários aspectos da vida social. Na área da saúde, verificam-se proposições e o desenvolvimento de alternativas para adequação do setor a essa ordem estabelecida. As premissas e os valores do projeto neoliberal fundamentam-se nos pressupostos da desresponsabilização do Estado quanto à garantia de direitos sociais, com diminuição do gasto social e focalização da assistência. Com isso, promove-se a separação entre a medicina comercial, envolvendo alta tecnologia e praticada por quem logra inserirse no projeto modernizador, e um pacote de serviços e ações essenciais para grupos marginalizados e excluídos do processo de mudança da sociedade (Laurell, 1997).

O sistema de saúde brasileiro, não obstante as conquistas do movimento da reforma sanitária e a criação do Sistema Único de Saúde (SUS), tem sido palco de disputa para dois projetos que se enfrentam e convivem contraditoriamente. De um lado, encontra-se o projeto da reforma sanitária fundamentado nos valores da solidariedade e em princípios de universalidade, integralidade e equidade; do outro, o projeto neoliberal, que defende a segmentação e a privatização como alternativas de organização do setor e que atribui aos próprios usuários a responsabilidade pelos serviços de saúde. Como política compensatória, o Estado só ofereceria, por meio de pacotes mínimos de serviços, assistência simplificada para pobres e indigentes (Mendes, 2001).

A forma de organização dos serviços de saúde, aliada aos valores sociais vigentes e ao modelo econômico e político, influencia diretamente a formação e o perfil dos profissionais da área. Toda formação profissional mantém estreita relação com o mundo laboral. As necessidades, demandas e exigências do mercado de trabalho, provocadas pela reestruturação produtiva, acabam, portanto, por influenciar, em maior ou menor proporção, a formação profissional (Catani, Oliveira, Dourado, 2001). Dessa forma, o papel a ser desenvolvido pelos profissionais pode variar entre o atendimento às exigências do mercado e o protagonismo na reversão da realidade epidemiológica.

A universidade tem destacada responsabilidade na condução da formação profissional voltada para a resolução dos problemas e necessidades sociais, e não apenas para o atendimento às regras estabelecidas pelo mercado privatista. Todavia, a força do projeto neoliberal tem atingindo o ensino superior e neutralizado o espaço universitário como campo de formação crítica, reflexiva e transformadora (Catani, Oliveira, Dourado, 2001). Paim (2002), ao debater Althusser, destaca a função da educação como reprodutora das desigualdades sociais, bem como o fato de que, através dos mecanismos culturais, as instituições de ensino contribuem para a manutenção da estrutura social capitalista. A universidade, nesse contexto, se constituiria em aparelho ideológico do Estado, responsável pela reprodução das relações de produção do tipo capitalista.

Entre os profissionais de saúde, o modelo de formação neoliberal-capitalista encontrou sólido alicerce no já estruturado modelo flexneriano-biologicista-privatista, que privilegiou o tecnicismo em detrimento das preocupações sociais e se fundamentou nos princípios da fragmentação, da especialidade e da cura (Paim, 2003). No que tange à formação de 
fisioterapeutas, esse problema é ainda mais agravado em virtude de a atuação desses profissionais voltar-se para o nível terciário. Gallo (2005) chama a atenção para o fato de que o fisioterapeuta, além de estar inserido no mesmo contexto dos demais profissionais da saúde com formação direcionada para a doença, padece desse infortúnio de forma mais acentuada, já que é visto como 'o profissional da reabilitação', ou seja, aquele que atua exclusivamente quando a doença, lesão ou disfunção já foi estabelecida.

Rebelatto e Botomé (1999), ao estudar o objeto de trabalho e a formação em fisioterapia no Brasil, destacam a limitação da prática fisioterapêutica direcionada para o indivíduo doente. Outros autores (Meyer, Costa, Gico, 2006; Silva, Da Ros, 2007) também referem a inadequação da formação em fisioterapia e sua descontextualização dos princípios do SUS e dos novos modelos de atenção. Na maior parte das instituições ainda predomina o modelo tecnicista, voltado para a cura de doenças e reabilitação de sequelas.

Diante desse contexto, o presente artigo tem por objetivo discutir a formação em fisioterapia no Brasil, problematizando aspectos referentes à expansão do ensino, ao campo de atuação e ao perfil profissional. Inicialmente apresenta-se a evolução da abertura de novos cursos, destacando a rápida expansão do número de vagas decorrente da ampliação do ensino superior privado no país e do reconhecimento social da fisioterapia. Posteriormente, discute-se o campo de atuação do fisioterapeuta, com ênfase na contradição entre saturação do mercado privado de assistência e carência assistencial da população. Por fim, avalia-se a inadequação do modelo de formação à nova realidade epidemiológica e sanitária e destacam-se algumas iniciativas com potencial de contribuir para a transformação do perfil profissional.

\section{Expansão do ensino da fisioterapia no Brasil}

A fisioterapia surgiu no país a partir de 1929, com a criação do primeiro curso técnico na Santa Casa de Misericórdia de São Paulo (Pereira, Almeida, 2006). A motivação principal para sua criação foi o grande número de portadores de sequelas da poliomielite - então com elevada incidência - com distúrbios do aparelho locomotor, bem como o crescente aumento de acidentes de trabalho. Considerada profissão recente, com menos de quarenta anos de regulamentação, a formação em fisioterapia no Brasil evoluiu de forma lenta nas décadas de 1970 e 1980, elevou consideravelmente o número de cursos e de vagas na década de 1990 e atingiu acelerada expansão a partir de 1997.

Durante a primeira metade do século passado, o quadro epidemiológico brasileiro caracterizou-se pelo predomínio de doenças infecciosas e parasitárias, sobretudo as epidemias de varíola, malária, febre amarela, poliomielite, tuberculose e sífilis (Barata, 2000). Essas doenças e suas sequelas ocasionaram a diminuição da mão de obra disponível, o que pressionou o Estado no sentido de garantir força de trabalho. A reação veio sob a forma do sanitarismo campanhista, que objetivava debelar as grandes epidemias que assolavam o país.

Nesse período, o Brasil também passou por mudança de sua economia, deixando a condição de país agroexportador para adotar o modelo de produção capitalista, com o surgimento das primeiras indústrias (Paim, 2003). Em decorrência, cresceu o número de 
trabalhadores acidentados e lesionados e a conseqüente necessidade de reinserção desses trabalhadores no mercado de trabalho. Assim surgiu a fisioterapia como instrumento de reabilitação da mão de obra e sua reintegração à força produtiva. Compreendia-se, à época, a saúde como instrumento de sustentação econômica e não como direito social da população.

A regulamentação da fisioterapia como profissão de nível superior ocorreu em 1969, com o decreto-lei 938 (Brasil, 16 out. 1969), no auge da ditadura militar no país e quando se agravaram as condições de saúde da população devido à sobrecarga epidemiológica e à deficiência do sistema assistencial brasileiro. Também nesse período intensificou-se o agravamento das condições de vida da população, em consequência do modelo econômico concentrador de renda. A política de privilégio para as grandes corporações, com forte incentivo ao crescimento industrial, desenvolveu-se em paralelo à deterioração das conquistas da classe trabalhadora (Paim, 2003). O desenvolvimento da fisioterapia aconteceu, portanto, em momento turbulento da sociedade brasileira, de forte crise no setor saúde e com grandes implicações para a população.

No Brasil, a formação em fisioterapia sofre, ao longo de sua história, influência dos contextos políticos, econômicos e sociais. Em 1969, quando da regulamentação da profissão, existiam no Brasil apenas seis cursos dessa graduação (Gráfico 1). Em 15 anos surgiram mais 16, totalizando 22 cursos em 1984. Nessa fase o crescimento da oferta de vagas foi lento, o que se pode explicar por dois fatores principais: a pequena expansão do ensino superior no país, em decorrência da repressão do regime militar à educação superior, foco de resistência do regime ditatorial, e o pouco conhecimento das competências e dos benefícios da fisioterapia sobre a saúde da população. Durante a década de 1980 e a primeira metade da seguinte, a expansão dos cursos de fisioterapia seguiu a mesma tendência de crescimento lento, atingindo o total de 63 em 1995.

Gráfico 1 - Número de cursos de fisitoerapia no Brasil, 1969-2008

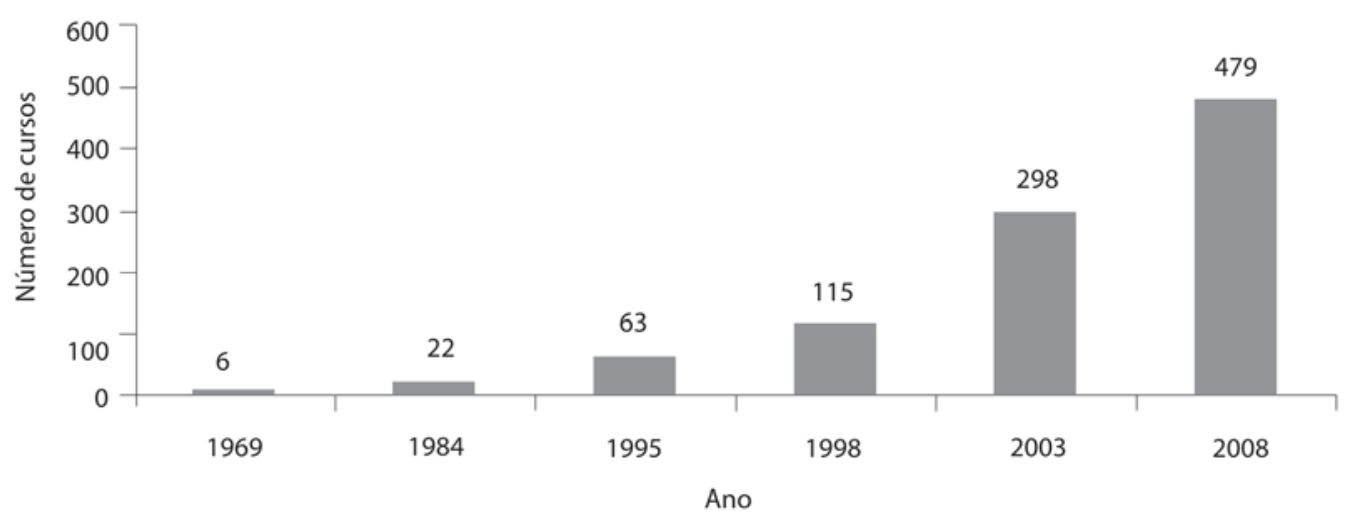

A partir da segunda metade dos anos 1990, a abertura de novos de cursos aumentou de maneira exponencial: como aponta o Gráfico 1, entre 1995 e 1998, de 63 para 115, o que corresponde a crescimento de mais de 80\%. Essa rápida expansão acelerou-se nos anos subsequentes. Entre 1999 e 2003, o número de cursos saltou de 115 para 298, o que representa 
aumento de $159 \%$ em apenas cinco anos; nos cinco anos posteriores, o crescimento de 60\% levou ao total de 479 cursos em 2008 (Gráfico 1). Resumindo, nos últimos dez anos a quantidade de cursos e a oferta de vagas de fisioterapia no Brasil aumentaram em mais de 300\%, com a criação de 364 novos cursos. Esse crescimento a partir da segunda metade da década de 1990 foi motivado pela inversão dos valores que o impediram nos anos 1970, uma vez que o principal fator determinante foi a política, adotada pelo Estado brasileiro, de corrigir o déficit da escolaridade superior no país. Dessa forma, todas as áreas do conhecimento e todas as profissões passaram por processo de ampliação do número de cursos e de vagas (Neves, Raizer, Fachinetto, 2007). Outra motivação refere-se ao reconhecimento e respeito atribuídos à fisioterapia e à grande valorização da profissão pela sociedade. Mesmo no processo geral de expansão do ensino superior, a graduação em fisioterapia se destaca como um dos um dos cursos de maior crescimento da área de saúde.

Com a redemocratização do país, os governos eleitos iniciaram o processo de reforma política e econômica, incorporando as ideias de Estado-mínimo e eficiência da gestão pública. Essas reformas, pautadas nos princípios neoliberais de globalização e sob forte influência dos organismos financeiros internacionais, sustentaram-se nos princípios de ajuste macroeconômico, equilíbrio orçamentário - sobretudo mediante a redução dos gastos públicos -, abertura comercial e liberalização financeira, bem como descentralização e privatização de empresas estatais e desresponsabilização do Estado quanto à garantia de direitos sociais (Corbucci, 2004). Todavia, contrariamente ao anunciado, os resultados têm sido o aprofundamento das desigualdades sociais e o aumento da pobreza e de suas mazelas. A modernização brasileira não tem conseguido alcançar os padrões visados e não trouxe o bem-estar esperado (Vaidergom, 2001).

Na educação superior, o projeto neoliberal, sob pretexto de ampliação da oferta, incentivou e promoveu a liberalização do ensino à iniciativa privada, sem, no entanto, incentivar a ampliação da rede pública, em especial das instituições federais. Para tanto, o Conselho Nacional de Educação acelerou e facilitou os processos de autorização, reconhecimento e credenciamento de cursos e instituições particulares (Corbucci, 2004). A expansão do ensino superior desenvolveu-se de forma desregulada e provocou inúmeras consequências. Entre os principais problemas da mercantilização da educação superior no Brasil, destacam-se: inexistência de planejamento; baixa qualidade do ensino; e desequilíbrios entre áreas de conhecimento e entre regiões geográficas (Macedo et al., 2005).

Com relação à fisioterapia, a ampliação do número de cursos e vagas também ocorreu de forma desregulada, desencadeando os problemas referidos. Os cursos de fisioterapia expandiram-se sem planejamento e regulação, em meio à estagnação das instituições de ensino superior públicas e ao incentivo às instituições privadas. Pereira e Almeida (2006) chamam a atenção para dois aspectos concernentes a essa expansão: a concentração geográfica dos cursos e a privatização do ensino.

Em 2003, a distribuição de cursos por região assim se apresentava: $181(60,7 \%)$ na região Sudeste; $57(19,1 \%)$ na região Sul; $17(5,8 \%)$ na região Centro-Oeste; 35 (11,7\%) na região Nordeste; e oito (2,7\%) na região Norte (Pereira, Almeida, 2006). A distribuição da população residente por regiões, no mesmo período, aponta: Sudeste, 42,62\%; Sul, 14,69\%; Centro-Oeste, 7\%; Nordeste, 27,84\%; e Norte, 27,84\% (IBGE, s.d.). Comparando-se as 
distribuições de cursos e populações, evidenciam-se grandes discrepâncias entre as regiões: enquanto Sul e Sudeste concentravam $80 \%$ dos cursos e $57,31 \%$ da população, Norte e Nordeste, com 35,69\% da população do país, possuíam 14,4\% dos cursos. A desigualdade na distribuição dos cursos é algo preocupante, com potenciais reflexos na assistência prestada à população, em virtude tanto da carência de profissionais em algumas localidades, a exemplo da região Norte, quanto de divergências corporativas nas regiões de maior concentração profissional, a exemplo do Sudeste.

Com relação à natureza administrativa das instituições de ensino, verifica-se que a expansão da fisioterapia ocorreu majoritariamente a partir da iniciativa privada. Em 1995, dos 63 cursos existentes, 46 (73\%) eram da rede privada e 17 (27\%), da rede pública. Em 2003, esses números eram $263(88,2 \%)$ e 35 (11,8\%), respectivamente, demonstrando a tendência à privatização do ensino da fisioterapia (Pereira, Almeida, 2006). Embora se deva destacar que a rede pública ampliou o número de cursos em mais de $100 \%$ no período observado, o aumento se apresenta de forma muito mais expressiva na rede privada.

\section{Formação profissional, mercado de trabalho e necessidades assistenciais}

Ao analisar o campo de atuação profissional, percebe-se clara contradição entre o número de profissionais existentes e as necessidades de assistência da população. De um lado, encontra-se grande contingente de profissionais aptos a prestar assistência; de outro, a população desassistida e com carência de oferta de serviços de saúde. A solução para esse descompasso demanda a intervenção de mediador coletivo (Frenk, 1994), capaz promover a integração das demandas sociais à capacidade de assistência dos profissionais. Nesse caso, o mediador coletivo é o Estado, mais precisamente o SUS. O Quadro 1 demonstra o diagrama dessa mediação.

No caso específico de um sistema público como o SUS, fundamentado nos princípios da universalidade, integralidade e equidade, cabe ao Estado não apenas sua regulação, mas também seu financiamento e a prestação da assistência. Nesse sentido, destaca-se a urgência de maior intervenção do Estado no cuidado da saúde físico-funcional da população. O diagrama apresentado no Quadro 1 indica que o SUS deve mediar a demanda de assistência e a oferta potencial dos profissionais e das instituições prestadoras de serviços, como também gerar as condições para transformação do nível de saúde populacional.

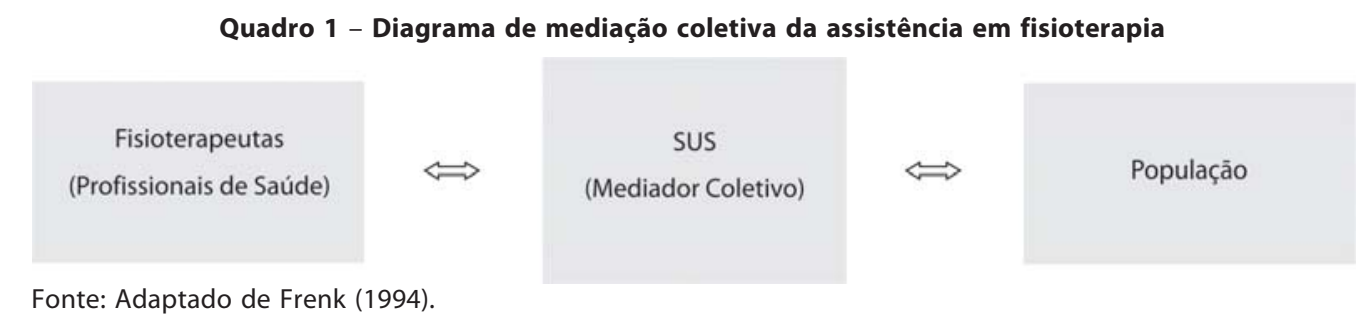

Todavia, a ação do SUS visando aproximar a área de fisioterapia e as demandas da população não pode ocorrer fundamentada nas práticas de atuação profissional exclusivamente reabilitadoras. A fisioterapia, ao longo de sua história, atuou de modo prioritário 
no nível terciário, destinando-se à cura de determinadas enfermidades e/ou à reabilitação de sequelas e complicações. Seu objeto de intervenção tem sido o sujeito individualizado, quando não apenas partes ou órgãos isolados de seu corpo. Um dos fatores que contribuem para explicar essa situação é a própria opção da fisioterapia em constituir-se como profissão liberal, direcionada para o atendimento à classe média e aos estratos de maior poder econômico. Durante muitos anos, o fisioterapeuta atuou como profissional autônomo, com atividade desenvolvida quase sempre em clínicas privadas, centros de reabilitação ou hospitais e voltada para a reabilitação de disfunções do sistema musculoesquelético. Parece ter ocorrido certa letargia, por parte desses profissionais, em discutir e apresentar proposições sobre as contribuições da fisioterapia para promoção da saúde e prevenção de doenças e sobre intervenção em âmbito coletivo.

A atuação dirigida apenas para a reabilitação impõe restrições à prática do fisioterapeuta, que se limita a intervir quando a doença já está instalada e, na maioria dos casos, de forma avançada. Rebelatto (1998) denomina essa situação "inércia profissional", caracterizada pela passividade dos profissionais, que só atuam em face de problemas de saúde já instalados e só prestam assistência aos que procuram os serviços quando não suportam mais sua condição patológica. Nesse caso, destacam-se como lócus de atuação o hospital e a clínica de reabilitação, espaços tradicionalmente estabelecidos e popularmente valorizados para a prática fisioterapêutica. A priorização desses espaços condiciona e restringe as possibilidades de intervenção em apenas um nível de atenção, a reabilitação. Tal situação impõe à população grande carga de doenças e sequelas que poderiam ser, muitas vezes, evitadas.

Ao analisar o atual campo de atuação profissional do fisioterapeuta, percebe-se o que se chama de saturação do mercado de trabalho': com a ampliação do número de cursos e, consequentemente, maior oferta de profissionais, observam-se diminuição ou quase extinção da oferta de empregos em algumas regiões e a precarização dos vínculos e condições de trabalho. Essa situação foi potencializada em virtude de a ampliação dos cursos de fisioterapia fundamentar-se na lógica curativo-reabilitadora, flexneriana. O modelo de formação flexneriano fundamenta-se no paradigma biologicista e valoriza a tecnificação do ensino, o estímulo à especialização e a ênfase na pesquisa biológica (Campos, Aguiar, Belisário, 2008). Embora tenha contribuído para o avanço tecnocientífico na área de saúde, ele se tornou inadequado por promover formação excessivamente tecnicista e com visão privatista da assistência. No Brasil, o que se convencionou chamar de modelo flexneriano diz respeito às mudanças de formação das escolas médicas, que acabaram por influenciar também a formação de outras profissões da área da saúde. O relatório de Abran Flexner, em 1910, teria promovido grandes mudanças no ensino médico americano e também em outros países. Cabe destacar, no entanto, que a formação médica já experimentava transformações influenciadas pelas escolas europeias e que as reformas de Flexner se aproveitaram de forças e ideias já existentes no ensino médico dos EUA e da Alemanha. No Brasil, esse campo de ensino esboçava mudanças no começo do século XX, anteriores a Flexner, para um padrão indiscutivelmente mais próximo da especialidade e do laboratório (Kemp, Edler, 2004).

Fato é que, no país, ao seguir a lógica privatista de formação para o mercado de trabalho, a ampliação do número de cursos não resultou em ampliação da assistência ou maior acesso da população aos cuidados da fisioterapia. A população brasileira ainda convive 
com grande dificuldade de acesso aos serviços de saúde, complexa carga de doenças e agravos à saúde e, sobretudo, com precárias condições de vida, incompatíveis com nível satisfatório de saúde (Paim, 2002). No que concerne especificamente à saúde físico-funcional, observa-se elevada prevalência de disfunções relacionadas à locomoção humana. O Censo Demográfico de 2000 (IBGE, 2001) identificou 24,5 milhões de pessoas com algum tipo de deficiência, o que equivale a $14,5 \%$ da população brasileira. Com relação às deficiências físicas e motoras, são 6,6 milhões de habitantes, correspondendo a 3,9\% da população. $O$ relatório do Ministério da Justiça (Brasil, 2004) sobre prevalência de deficiências, incapacidades e desvantagens, que sistematizou inquéritos realizados em 21 cidades brasileiras das cinco regiões do país, apontou prevalência de incapacidades variando de $2,8 \%$ a $9,7 \%$ e no que se refere à incapacidade de locomoção, de 0,3\% a 3,6\%. Chama a atenção, nos dois estudos, a relação entre o nível de desenvolvimento econômico e social e a prevalência de deficiências e incapacidades. Observa-se relação inversa entre o nível de escolaridade e a prevalência de deficiência, demonstrando que, quanto maior o número de anos de estudo, menor a proporção de pessoas com deficiência (IBGE, 2001; Brasil, 2004).

As incapacidades estão diretamente relacionadas com a qualidade do atendimento à saúde. Os serviços de saúde não suprem as necessidades da população, em termos de cobertura e/ou qualidade de atendimento. Além do mais, em todas as cidades estudadas constatouse que os prognósticos eram bastante positivos, apresentando índices significativos de casos com possibilidade de melhora, assistência e recuperação (Brasil, 2004). Dessa forma, a chamada saturação do mercado de trabalho da fisioterapia não corresponde à plenitude da atenção à saúde da população. O que se encontra saturado é o campo privado de atuação curativista, orientado pela lógica do lucro, ao qual o acesso é determinado pela capacidade de pagamento e não pelas necessidades individuais ou coletivas.

Constata-se, ainda, que grande parte das incapacidades está relacionada aos hábitos e condições de vida, sendo portanto evitável e passível de prevenção (Brasil, 2004). Grupo significativo de deficiências decorre de doenças crônicas, como hipertensão arterial (acidentes vasculares cerebrais) e diabetes (amputações, neuropatias, cegueira), ou de riscos na gravidez, parto e puerpério (paralisia cerebral), ou ainda de causas externas. Dessa forma, pode-se considerar que, contrariamente à existência de excesso de profissionais, o que ocorre é a carência de fisioterapeutas em atuação nos níveis primário e secundário. Não basta que o SUS, como mediador coletivo, proporcione a aproximação entre a fisioterapia e as necessidades da população; a fisioterapia deve adequar-se e preparar-se para atuar de acordo com a nova lógica de organização dos modelos de atenção e o atual perfil epidemiológico da população.

Para uma atuação capaz de transformar as necessidades coletivas, a fisioterapia precisa redimensionar seu objeto de intervenção, que deve aproximar-se do campo da promoção da saúde e do movimento da saúde coletiva sem abandonar suas competências concernentes à reabilitação. Esse redimensionamento do objeto de intervenção e da práxis profissional conduz a mudanças mais profundas, de natureza epistemológica, na concepção e atuação do fisioterapeuta. 


\section{Modelo de formação e perfil profissional}

Com relação ao modelo de formação e ao perfil dos profissionais egressos, observa-se clara hegemonia de formação com perfil curativo-reabilitador privatista, condição que se originou daquela em que foi criada a profissão, com o objetivo de reabilitar indivíduos com sequelas de traumas e lesões no sistema musculoesquelético. Esse modelo de formação reabilitadora persistiu durante muitos anos, mesmo com mudanças significativas no perfil epidemiológico da população e na organização do sistema de saúde brasileiro. Só a partir do início do século XXI surgiram as primeiras iniciativas para a mudança do modelo de formação.

Com a promulgação do decreto-lei 938/69, a profissão ganhou status de nível superior e adquiriu responsabilidades privativas relacionadas à restauração, ao desenvolvimento e à conservação do movimento humano. O referido decreto-lei deu início a período distinto da fisioterapia no Brasil, que, todavia, não foi acompanhado de aparato jurídico-legal ou teórico concernente à formação profissional ou ao perfil dos novos profissionais. Só após 14 anos de regulamentação da profissão, em 1983, o Conselho Federal de Educação (CFE) estabeleceu os currículos mínimos para a formação de fisioterapeutas (Brasil, 28 fev. 1983). De acordo com a Resolução 4/83, o CFE instituiu o tempo de formação do fisioterapeuta em quatro anos e com pelo menos 3.240 horas, bem como determinou que as disciplinas integrantes do currículo mínimo deveriam ser divididas em quatro ciclos de matérias: biológicas; de formação geral; pré-profissionalizantes; e profissionalizantes.

Devido ao modelo curativo de atenção à saúde desenvolvido no país no período militar e à ausência de regulamentação curricular na década de 1970, a fisioterapia consolidou-se como profissão reabilitadora e direcionou-se para o nível terciário. No que diz respeito a desenvolvimento e reconhecimento da fisioterapia pelas demais profissões da área de saúde, esse período constituiu-se como alicerce para valorização e reconhecimento dos benefícios e das potencialidades da profissão junto à equipe de saúde. Na década de 1980, o estabelecimento do currículo mínimo para a formação em fisioterapia (Brasil, 28 fev. 1983) reforçou a posição da profissão de se pautar pelo modelo curativo-reabilitador.

Nos anos 1990 iniciou-se a expansão do número de cursos de fisioterapia no Brasil. Quanto ao modelo de formação, entretanto, as instituições de ensino mantiveram e aprofundaram o curativo-reabilitador privatista, formando fisioterapeutas a partir da concepção de profissional liberal. Estimulou-se o aprimoramento tecnicista sob o discurso da crescente concorrência do mercado de trabalho, em que o domínio do conhecimento biológico e das técnicas de reabilitação era requisito suficiente e necessário para o estabelecimento no mercado.

Do ponto de vista epidemiológico e sanitário, duas características principais marcaram a década: a consolidação da transição epidemiológica e a criação do SUS, com mudanças no modelo de atenção à saúde. No Brasil, a transição epidemiológica ocorreu de forma complexa, convivendo as doenças infecciosas e parasitárias (sempre presentes em meio à pobreza e ao subdesenvolvimento) com as da modernidade (doenças crônicas não transmissíveis e óbitos e agravos decorrentes de causas externas) (Barreto, Carmo, 2007).

Com relação à organização do sistema de saúde, a promulgação das leis 8.080/90 e $8.142 / 90$, que criaram e regulamentaram o SUS, constituiu marco do novo modelo de 
atenção à saúde, segundo o qual devem ser priorizadas as ações promocionais e preventivas sem prejuízo das assistenciais. No entanto, contraditoriamente, houve o crescimento da assistência privada e suplementar, em paralelo ao desenvolvimento do sistema público, universal e integral. Com a universalização da atenção à saúde e a inclusão de mais de 60 milhões de brasileiros, até então indigentes sanitários, houve a migração de parcela importante da população, em especial da classe média, que optou pelo sistema suplementar de atenção à saúde, o que estimulou seu crescimento e desenvolvimento (Mendes, 2001).

Diante desse contexto, a fisioterapia optou por direcionar sua atuação para o sistema suplementar de assistência, e convênios e planos de saúde constituíram, quase sempre, requisitos necessários para o acesso aos serviços de fisioterapia. Frente aos desejos e necessidades dos usuários-pagantes, a fisioterapia aperfeiçoou-se e desenvolveu novas especialidades, a exemplo da fisioterapia estética, drenagem linfática, reeducação postural global, pilates e acupuntura. A profissão elitizou-se, o acesso dos usuários do sistema público tornou-se ainda mais difícil e a qualidade do atendimento não acompanhou a evolução do sistema privado.

Assim, na década de 1990 a fisioterapia cresceu em relação ao status profissional e ampliou suas especializações e seu campo de atuação, o que, no entanto, ocorreu majoritariamente no nível terciário de atenção e sob a lógica privatista da assistência, condição afetada e estimulada pelo aumento do número de cursos. Esses fatores têm contribuído para a dificuldade de ampliação do campo de atuação da fisioterapia, em virtude do inadequado perfil profissional para atuação em outros níveis. Silva e Da Ros (2007) chamam a atenção para a limitada compreensão, por parte de profissionais e estudantes, das possibilidades de atuação do fisioterapeuta na atenção básica. Segundo Meyer, Costa e Gico (2006), a estrutura, a metodologia de ensino e a organização curricular dos cursos de fisioterapia ainda não se baseiam nas demandas sociais e nas políticas públicas de saúde, e existe pouco envolvimento dos discentes e docentes com políticas institucionais e governamentais.

No início do século XXI parece haver o despertar para a necessidade de redimensionamento do modelo de formação em fisioterapia e da construção de outro perfil profissional. Algumas iniciativas demonstram as preocupações com a inadequação do perfil profissional à realidade epidemiológica e sanitária, e iniciam um processo de transformação do ensino da fisioterapia no Brasil.

Com a criação da Associação Brasileira de Ensino em Fisioterapia (Abenfisio), entidade que congrega docentes, discentes e coordenadores de cursos de graduação, aprofundam-se os debates sobre a formação em fisioterapia. A entidade promove semestralmente fóruns nacionais de discussão a respeito do ensino da fisioterapia, nos quais se realizam avaliações e se discutem a qualidade do ensino e o modelo de formação. Também são estruturadas novas propostas e abordagens de ensino, com formação fundamentada nos princípios do SUS e articulada com os saberes da saúde coletiva.

A Carta de Vitória (2004), documento-síntese do 1o Congresso Nacional do Ensino da Fisioterapia, constitui referencial para a qualidade da formação na área. O documento sublinha os principais problemas do ensino da fisioterapia e propõe algumas medidas de referência para a qualidade do ensino: carga de 4.500 horas; adequação dos currículos às necessidades regionais; incorporação de princípios e diretrizes do SUS no processo de 
formação; e desenvolvimento de práticas comunitárias. Ainda como parte integrante do processo de mudança na formação profissional em fisioterapia, destacam-se as contribuições da Rede Unida na mobilização, aglutinação, discussão, crítica e proposição de novos modelos de formação em saúde no país, em que a formação em fisioterapia tem obtido crescente destaque.

O Conselho Nacional de Educação instituiu, em 2002, as Diretrizes Curriculares Nacionais do Curso de Graduação em Fisioterapia, marco importante na orientação e transformação do ensino em que são definidos princípios, fundamentos e condições para a formação em todas as instituições nacionais de ensino. O perfil do profissional egresso deve revelar-se generalista com formação crítica, humanista e reflexiva, e com capacitação para atuar em todos os níveis de atenção. Define ainda como objeto de trabalho da profissão o movimento humano em todas as suas dimensões, e destaca que a responsabilidade da atenção à saúde não se encerra com o ato técnico, mas sim com a resolução do problema em âmbito tanto individual como coletivo (Brasil, 2003).

Embora as diretrizes curriculares sejam criticadas porque não estabelecem carga horária mínima para os cursos (Carta de Santa Cruz do Sul, 2001) e porque possibilitam excessiva flexibilização na formação universitária (Catani, Oliveira, Dourado, 2001), elas configuram instrumento imprescindível para a garantia da qualidade do ensino, posto que estabelecem padrões mínimos nacionais e direcionam a formação de acordo com realidade epidemiológica e com os novos modelos de atenção à saúde.

\section{Considerações finais}

Este artigo apresenta algumas reflexões sobre a formação em fisioterapia no Brasil, com destaque para o processo de ampliação do número de cursos e vagas, e a adequação do modelo de formação às necessidades de saúde da população. Cabe lembrar que ele não encerra a discussão do assunto, mas pretende instigar e enriquecer o debate sobre os aspectos relacionados à formação em fisioterapia.

Como síntese, são apresentadas algumas proposições com o intuito de contribuir para a mudança do modelo de formação e para a aproximação entre as necessidades sociais da população e as competências e potencialidades da fisioterapia. É necessário o estabelecimento de mais rigor, por parte das autoridades governamentais, com relação à abertura de novos cursos e novas instituições de ensino superior no país. Os ministérios da Educação e Saúde devem atuar conjuntamente no processo de regulação da criação de vagas, utilizando como critérios a capacidade da instituição em oferecer ensino de qualidade e a necessidade de profissionais para cada região e áreas adjacentes.

A decisão de abertura de novos cursos não pode ser pautada em estudos de viabilidade econômica ou de nichos de mercado, devendo antes fundamentar-se em necessidades sociais e considerar as contribuições de cada novo curso para a transformação da realidade social e epidemiológica. Chama-se a atenção, também, para a necessidade da ampliação do número de vagas nas instituições públicas, que devem liderar a ampliação do ensino superior no país. Destaca-se ainda, a responsabilidade das universidades na produção de novos conhecimentos e na formação de profissionais críticos e socialmente comprometidos. 
Elas não se podem restringir ao papel de meras reprodutoras de um modelo de formação ultrapassado e inadequado ao sistema de saúde, cabendo-lhes sim a responsabilidade de produzir novos saberes e novas formas de atuação apropriadas às necessidades da população.

Torna-se necessário promover o rompimento com o modelo de formação curativoreabilitador privatista. Os cursos de fisioterapia, conforme instituído nas diretrizes curriculares nacionais, devem estruturar-se a partir dos princípios do SUS e adequar a formação dos profissionais ao perfil epidemiológico da população. O objeto de trabalho da profissão continuará sendo o movimento humano. A responsabilidade profissional, no entanto, não se restringirá ao nível terciário da reabilitação, mas deverá ampliar-se para os níveis primário e secundário. A formação, portanto, deve aproximar-se do paradigma da promoção da saúde e do campo da saúde coletiva, alargando as possibilidades de atuação, direcionadas, prioritariamente, para os determinantes e condicionantes do processo saúde/ doença.

A aproximação entre fisioterapia e saúde coletiva tem como propósito ampliar o campo de prática da profissão e disponibilizar para a sociedade novos saberes capazes de contribuir para a promoção da saúde e qualidade de vida. A defesa da inserção da fisioterapia na saúde coletiva, em especial na atenção básica, não se pode restringir aos propósitos da ampliação do mercado de trabalho do fisioterapeuta; acima de tudo, deve pautar-se na responsabilidade social inerente a todas as profissões da área de saúde.

A visão mercadológica da ampliação da atenção básica, com o intuito de inclusão de profissionais na estratégia de saúde da família só para ampliar mercado de trabalho, deve ser condenada e combatida. Cabe à fisioterapia promover mudanças profundas, de natureza conceitual e epistemológica, sobre seus saberes e campos de prática e apresentar, para a sociedade, as contribuições de sua atuação nos níveis primário e secundário. A visão mercadológica de ampliação da atenção básica é insuficiente para promover mudanças no perfil do profissional, que continuará a ser curativo-reabilitador. O novo modelo de formação em fisioterapia preconiza que a formação deve voltar-se não mais para atender às demandas do mercado, mas, sobretudo, para atender às necessidades da sociedade.

\section{NOTA}

${ }^{1} \mathrm{O}$ campo de atuação profissional relativo à saúde físico-funcional é disputado por fisioterapeutas e fisiatras, o que pode contribuir para agravar a referida saturação do mercado de trabalho. Essa disputa é permeada, sobretudo, por corporativismos e interesses mercadológicos que merecem reflexão detalhada e aprofundada. Como, porém, nosso propósito é discutir a formação em fisioterapia, tal temática não será abordada nesse artigo.

\section{REFERÊNCIAS}

BARATA, Rita Barradas.

Cem anos de endemias e epidemias. Ciência \& Saúde Coletiva, Rio de Janeiro, v.5, n.2, p.333345. 2000.

BARRETO, Maurício Lima; CARMO, Eduardo Hage.

Padrões de adoecimento e de morte da população brasileira: os renovados desafios para o Sistema Único de Saúde. Ciência \& Saúde Coletiva, Rio de Janeiro, v.12, supl, p.1779-1790. 2007.

BRASIL.

Conselho Federal de Educação. Resolução 4. Fixa os mínimos de conteúdos e duração dos cursos de fisioterapia e terapia ocupacional. Disponível em: http://www.prolei.inep.gov.br/ 
pesquisar.do;jsessionid $=\mathrm{A} 05389 \mathrm{~F} 814 \mathrm{EE} 4 \mathrm{C} 24 \mathrm{BA}$ 603F755C800E7D? codThesaurus $=37179$. Acesso em: 20 ago. 2009. 28 fev. 1983.

BRASIL.

Conselho Nacional de Educação. Diretrizes curriculares nacionais do curso de graduação em fisioterapia. In: Almeida, Márcio. Diretrizes curriculares nacionais para os cursos universitários da área de saúde. Londrina: Rede Unida. p.3036. 2003.

BRASIL.

Decreto-lei 938 de 13 de outubro de 1969. Provê sobre as profissões de fisioterapeuta e terapeuta ocupacional e dá outras providências. Diário Oficial da União, Brasília, n.197, seção 1, p.3658. 16 out. 1969.

BRASIL.

Ministério da Justiça. Relatório sobre a prevalência de deficiências, incapacidades e desvantagens. Niterói: Ministério da Justiça/ Coordenadoria Nacional para Integração da Pessoa Portadora de Deficiência; Associação Fluminense de Reabilitação. 2004.

CAMPOS, Francisco Eduardo; AGUIAR, Raphael Augusto Teixeira; BELISÁRIO, Soraya Almeida.

A formação superior dos profissionais do SUS In: Giovanella, Lígia et al. Políticas e sistema de saúde no Brasil. Rio de Janeiro: Editora Focruz. p.1011-1035. 2008.

CARTA DE SANTA CRUZ DO SUL.

Relatório elaborado no 5. Fórum Nacional de Docentes em Fisioterapia, 23-25 ago. 2001. Santa Cruz do Sul. Disponível em: http://site. abenfisio.com.br/atas/ATA_V_FORUM.doc $>$. Acesso em: 15 jan. 2008. 2001.

CARTA DE VITÓRIA.

Resoluções do 1. Congresso Brasileiro do Ensino em Fisioterapia, 2003. Vitória. Disponível em: http://site.abenfisio.com.br/ arquivos/CARTA_DE_VITÓTIA.doc. Acesso em: 15 jan. 2008. 2003.

CATANI, Afrânio Mendes; OLIVEIRA, João Ferreira; DOURADO, Luiz Fernandes. Política educacional, mudanças no mundo do trabalho e reforma curricular nos cursos de graduação no Brasil. Educação \& Sociedade, Campinas, v.22, n.75, p.67-83. 2001.

CORBUCCI, Paulo Roberto.

Financiamento e democratização do acesso à educação superior no Brasil: da deserção do Estado ao projeto de reforma. Educação \& Sociedade, Campinas, v.25, n.88, p.677-701. 2004.

FRENK, Julio.

Dimensions of health system reform. Health Policy, Amsterdam, v.27, p.19-34. 1994.
GALLO, Douglas Luciano Lopes.

A fisioterapia no Programa de Saúde da Família: percepções em relação à atuação profissional e a formação universitária. Dissertação (Mestrado) - Universidade Estadual de Londrina, Londrina. 2005.

IBGE

Instituto Brasileiro de Geografia Estatística. Censo demográfico de 2000. Brasília: IBGE. 2001.

IBGE

Instituto Brasileiro de Geografia Estatística. População residente no Brasil, segundo as grandes regiões e unidades da federação: 2003-2006. Disponível em: http://www.ibge.gov.br/home/ estatistica/economia/contasregionais/2003 2006/tabela05.pdf. Acesso em: 12 mar. 2009. s.d.

INEP

Instituto Nacional de Estudos e Pesquisas Educacionais Anísio Teixeira. Lista de cursos de graduação no país. Disponível em: http:// www.educacaosuperior.inep.gov. br/funcional/ lista_cursos.asp >. Acesso em: 17 jan. 2008. s.d.

KEMP, Amy; EDLER, Flávio Coelho.

A reforma médica no Brasil e nos Estados Unidos: uma comparação entre duas retóricas. História, Ciências, Saúde - Manguinhos, Rio de Janeiro, v.11, n.3, p.569-585. 2004.

LAURELL, Asa Cristina.

Impacto das políticas sociais e econômicas nos perfis epidemiológicos. In: Barata, Rita Barradas et al. (Org.). Equidade e saúde: contribuições da epidemiologia. Rio de Janeiro: Fiocruz; Abrasco. p.83-101. 1997.

MACEDO, Arthur Roquete et al. Educação superior no século XXI e a reforma universitária brasileira. Ensaio: Avaliação, Políticas Públicas e Educação, Rio de Janeiro, v.13, n.47, p.127-148. 2005.

MENDES, Eugênio Vilaça.

Os grandes dilemas do SUS. t.1. Salvador: Casa da Qualidade. 2001.

MEYER, Patrícia Froes; COSTA, Íris Céu Clara; GICO, Vânia Vasconcelos.

Ciências sociais e fisioterapia: uma aproximação possível. História, Ciências, Saúde - Manguinhos, Rio de Janeiro, v.13, n.4, p.877-890. 2006.

NEVES, Clarissa Eckert Baeta; RAIZER, Leandro; FACHINETTO, Rochele Fellini.

Acesso, expansão e equidade na educação superior: novos desafios para a política educacional brasileira. Sociologias, Porto Alegre, v. 9, n.17, p.124-157. 2007.

PAIM, Jairnilson Silva.

Políticas de saúde no Brasil. In: Rouquayrol, 
Maria Zélia; Almeida Filho, Naomar (Org.). Epidemiologia \& Saúde. 6. ed. Rio de Janeiro: Medsi. p.587-603. 2003.

PAIM, Jairnilson Silva.

Saúde: política e reforma sanitária. Salvador: ISC. 2002.

PEREIRA, Luciana Alves; ALMEIDA, Márcio. Fisioterapia. In: Fundação Oswaldo Cruz. Dinâmica das graduações em saúde no Brasil: subsídios para uma política de recursos humanos. Brasília: Ministério da Saúde. p.171-184. 2006.

REBELATTO, José Rúbens.

Fisioterapia cotidiana: ações profissionais e decorrências para a população. Revista de Fisioterapia da Universidade de São Paulo, São Paulo, v.5, n.1, p.36-48. 1998.
REBELATTO, José Rúbens; BOTOMÉ, Sílvio Paulo.

Fisioterapia no Brasil: fundamentos para uma ação preventiva e perspectivas profissionais. 2 . ed. São Paulo: Manole; 1999.

SILVA, Daysi Jung; DA ROS, Marco Aurélio. Inserção de profissionais de fisioterapia na equipe de saúde da família e Sistema Único de Saúde: desafios na formação. Ciência \& Saúde Coletiva, Rio de Janeiro, v.12, n.6, p.1673-1681. 2007.

VAIDERGORN, José.

Uma perspectiva da globalização na universidade brasileira. Cadernos Cedes, Campinas, v.21, n.55, p.78-91. 2001.

\section{$\rightarrow \rightarrow \rightarrow<<<$}

